\title{
Exploiting Structured Linked Data in Enterprise Knowledge Management Systems: An Idea Management Case Study
}

\author{
Adam Westerski and Carlos A. Iglesias \\ Universidad Politecnica de Madrid, \\ ETS Ingenieros de Telecomunicacion, \\ Madrid, Spain \\ westerski@dit.upm.es,cif@gsi.dit.upm.es
}

\begin{abstract}
In parallel to the effort of creating Open Linked Data for the World Wide Web there is a number of projects aimed for developing the same technologies but in the context of their usage in closed environments such as private enterprises. In the paper, we present results of research on interlinking structured data for use in Idea Management Systems - a still rare breed of knowledge management systems dedicated to innovation management. In our study, we show the process of extending an ontology that initially covers only the Idea Management System structure towards the concept of linking with distributed enterprise data and public data using Semantic Web technologies. Furthermore we point out how the established links can help to solve the key problems of contemporary Idea Management Systems.
\end{abstract}

Keywords-idea management; ontology; metadata; knowledge management; product development; process improvement; linked data

\section{INTRODUCTION}

The Semantic Web in its origins was supposed to be a remedy to information overflow of the ever-growing Internet where machines through analysis of content could help human to reach the desired data in a fast manner [1]. As the topic gained interest it became obvious that the same technologies aimed for organising the global Internet network can deliver value to internal, closed environments of large enterprises that suffer similar problems of information overflow and disorganization [2].

The first attempts in both areas have put a lot of effort in development of reasoning techniques and algorithms related to the artificial intelligence. However, as this approach did not succeed to bring the desired solutions to mainstream development, more lightweight approaches were born to introduce metadata annotations to the Web and their simplistic use. Among them is Linking Open Data [3] initiative and research gathered around it that tries to draw simple patterns for usage and publication of online metadata linked across independent systems.

In the following paper we conform to the trend of transforming the Web of Data into Web of Linked Data however we focus only on the benefits that it might bring to the enterprise and analyse the particular area of innovation

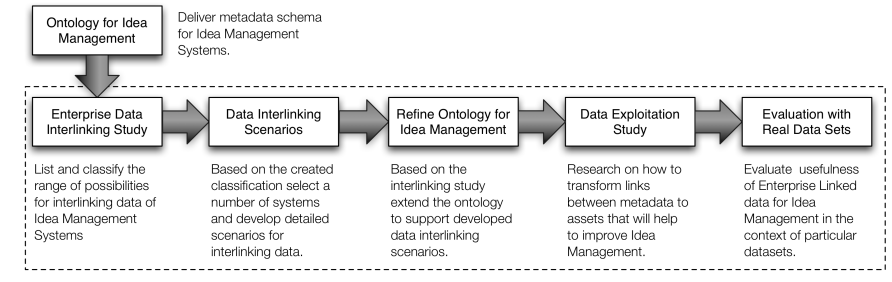

Figure 1. Research approach taken for investigating Enterprise Linked Data for Idea Management

management and interlinking various enterprise systems to support innovation processes in the organization. The principal research questions that we attempt to answer are: what enterprise systems and which of their data can be useful for innovation management, how to extend an existing innovation ontology towards linking data and finally how to utilize the connections to calculate innovation metrics.

In that context, we follow a research methodology (see Figure 1) that leads to extending the Generic Idea and Innovation Management Ontology (Gi2MO) [4] towards establishing links with enterprise systems and exploiting their data. In particular, we motivate our work with the desire to extract innovation metrics though analysis of linked data (see Sec. II). On the road to achieving this goal, we establish a classification of systems present in the idea management ecosystem and proceed with the analysis of their current status in terms of ontologies and interlinking efforts (see Sec. IV). Further, we show how the data can be exploited to create new capabilities for Idea Management Systems and propose particular interlinking methods (see Sec. V). Finally, we present the results of evaluation of our interlinking scenarios where we develop an analytic application that uses SPARQL queries to extract metrics from particular datasets and visualise them in a form of charts (see Sec. VI).

\section{Motivation}

Idea Management Systems (IMS) are a type of knowledge management systems that are used in organizations to gather 
input from large communities about innovation in products, services or even processes. The goal of such systems is to organize the input, assess it and produce a list of best ideas that will potentially deliver benefit to the organization.

One of the most important and troublesome stages is data assessment. Separating good ideas from bad is the core reason for existence of idea management. Currently, to perform this task, human reviewers fill out forms and deliver assessments which are the means for standardized comparison of ideas, their filtering and finally selecting the best candidates for implementation. On the other hand, the automatically generated metrics in most cases are limited to simple statistics derived from community activity (e.g. average number of comments in time per idea, per user etc.).

In relation to those activities the key problems of idea management are: information overflow (e.g. when a new product is announced by a company, the idea management facilities are flooded with new ideas), information redundancy (often ideas duplicate each other) or information triviality (simple and obvious ideas do not provide genuine value). Each of those issues impact in a negative way the idea assessment process and moderation activities which in turn discourages people from submitting new ideas because of slow feedback and little impact.

As an improvement over this state, in our research we propose to use datasets of other enterprise and public systems to supply additional data for idea management to generate new metrics and aid idea reviewers (see Fig. 2). In the next sections of this article we describe how we cope with this problem through use of Semantic Web technologies and specifically extending the Idea Management Ontology to facilitate various interlinking scenarios.

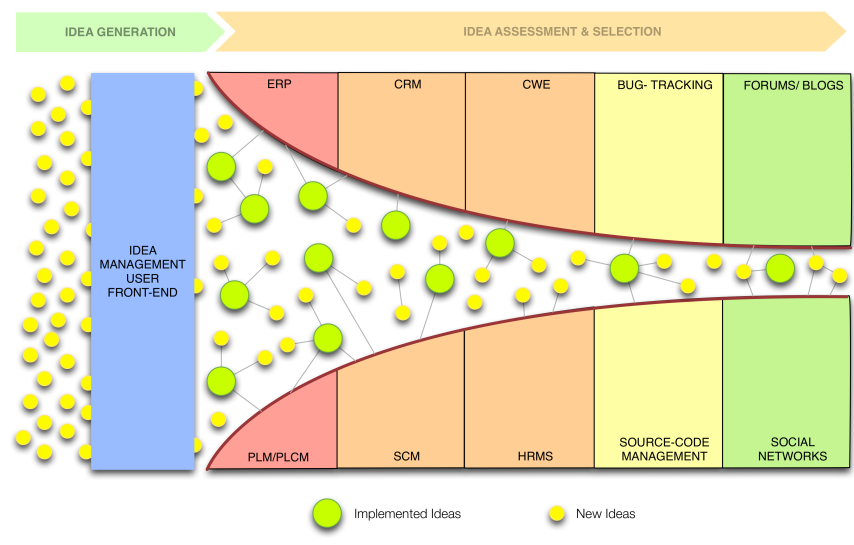

Figure 2. The concept of funnelling ideas based on their metrics derived from connections to data in other systems

\section{A Data Model AND An Ontology for IDEA MANAGEMENT SYSTEMS}

The research presented in this paper is a continuation of our studies conducted on creation of an ontology for Idea Management Systems (Gi2MO [4]). In our opinion the Idea Management Ontology is the basis to even start talking about Linked Data in the context of idea management. What it delivers is a solution for describing relationships present inside Idea Management Systems. For a detailed analysis of Idea Management System data model and options for publishing its data we send to our previous research [5] as well as other similar projects [6]. Here we only present a general view of the data contained in such systems in terms of introduction to the Idea Management Systems topic (see Fig. 3). The research presented in this paper starts from this level and focuses on the interlinking attempts which from our perspective are an evolutionary step in ontology creation to establish it in the contemporary Semantic Web research landscape that moves towards a more lightweight Linked Data paradigm.

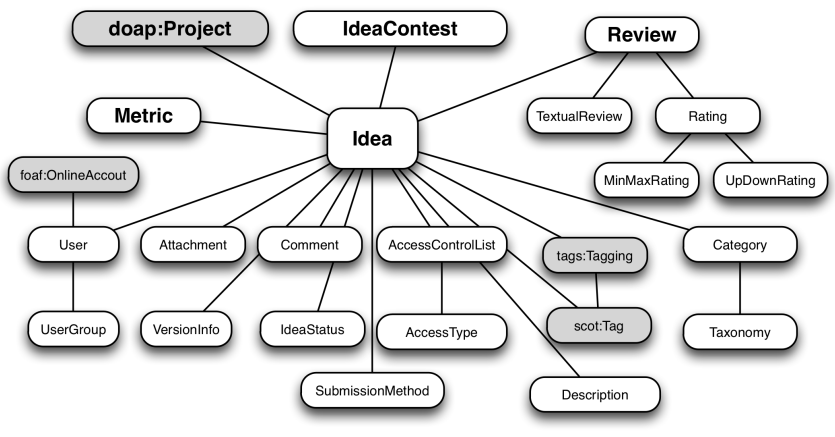

Figure 3. Schema of the concepts included in the Gi2MO ontology for Idea Management Systems

\section{ENTERPRISE DATA INTERLINKING STUDY}

In the following section we aim to face a challenge that is stated by the question: "What data can be used to interlink with Idea Management Systems?". Based on the origin of data valuable for idea management we propose to classify it into the following three categories, starting from least complex:

- interlining Idea Management System internal assets. The simplest case where we interlink only internal data of Idea Management System to deliver better tractability and allow analysis of how different phases of idea life cycle impact each other.

- interlinking internal data across the enterprise. This is a case of enterprise systems integration that are not shared with the public and transferring the benefits of that information onto Idea Management Platform. The 
Table I

ONTOLOGIES FOR ENTERPRISE SYSTEMS

\begin{tabular}{|c|c|c|c|c|}
\hline Scope & System Name & Acronym & Goal & Ontology \\
\hline Internal & $\begin{array}{l}\text { Idea Management Sys- } \\
\text { tem }\end{array}$ & IMS & Collect and manage ideas & Gi2MO [4], IO [7] \\
\hline & \multicolumn{4}{|c|}{ Global Approaches to Enterprise Management } \\
\hline Enterprise & $\begin{array}{ll}\text { Enterprise } & \text { Resource } \\
\text { Planing } & \end{array}$ & ERP & Manage business execution & $\begin{array}{l}\text { REA [8], [9], [10], } \\
\text { TOVE [11], EO [12], E3 } \\
\text { [13], BMO [14] }\end{array}$ \\
\hline \multirow[t]{2}{*}{ Enterprise } & $\begin{array}{l}\text { Product Life Cycle Man- } \\
\text { agement }\end{array}$ & PLM/PLCM & $\begin{array}{l}\text { Manage product development and engi- } \\
\text { neering }\end{array}$ & SOM based [15] \\
\hline & \multicolumn{4}{|c|}{ Specialised (Dedicated) Systems for Enterprise Management } \\
\hline Enterprise & $\begin{array}{l}\text { Client Relationship Man- } \\
\text { agement }\end{array}$ & CRM & Manage input from customers & $\begin{array}{l}\text { CMMI based [16], O- } \\
\text { CREAM [17], Customer } \\
\text { Ont. [18] }\end{array}$ \\
\hline Enterprise & $\begin{array}{l}\text { Supply Chain Manage- } \\
\text { ment }\end{array}$ & SCM & Manage the flow of products, services & $\begin{array}{l}\text { SCOR based [19], SCM } \\
\text { Ontologies [20], [15] }\end{array}$ \\
\hline Enterprise & Project Management & PMS & $\begin{array}{l}\text { Plan the project, assign tasks and set } \\
\text { deadlines }\end{array}$ & $\begin{array}{l}\begin{array}{l}\text { PROMONT [21], } \\
\text { [22], IT-CODE } \\
\text { DOAP [24] }\end{array} \\
\end{array}$ \\
\hline Enterprise & $\begin{array}{l}\text { Human Resources Man- } \\
\text { agement System }\end{array}$ & HRMS & Gather information about employees & $\begin{array}{lr}\text { Organization } & \text { ontology } \\
{[25],} & \text { Reference } \\
\text { Ontology } & {[26],} \\
\text { ResumeRDF }[27] & \end{array}$ \\
\hline \multirow[t]{2}{*}{ Enterprise } & $\begin{array}{l}\text { Collaborative } \text { Working } \\
\text { Environment }\end{array}$ & CWE & Share documents and information & SIOC [28] \\
\hline & \multicolumn{4}{|c|}{ Product Development Support Systems (Examples for Software Development) } \\
\hline Enterprise & Bug-tracking System & - & Collect and organize issues & BAETLE [29] \\
\hline Enterprise & $\begin{array}{l}\text { Software Configuration } \\
\text { Management }\end{array}$ & SCM & Manage configuration aspects & $\begin{array}{l}\text { SCM ontologies [30], } \\
{[31]}\end{array}$ \\
\hline Public & Blog/Forum/Lists & - & $\begin{array}{l}\text { Publish information and engage into dis- } \\
\text { cussions }\end{array}$ & SIOC [32], [33] \\
\hline Public & $\begin{array}{l}\text { Idea Management Sys- } \\
\text { tem }\end{array}$ & - & Collect and manage ideas & Gi2MO [4], IO [7] \\
\hline Public & Social Networks & - & $\begin{array}{l}\text { Connect with other people and pub- } \\
\text { lish/access personal data }\end{array}$ & SIOC [32], FOAF [34] \\
\hline Public & Wikis & - & $\begin{array}{l}\text { Publish information and collaborate on } \\
\text { improving it }\end{array}$ & SWIVT [35], [36] \\
\hline Public & Online Patent Databases & - & Collect and publish patent information & PSO [37] \\
\hline Public & Mindmapping & - & Create and publish mind maps & $\begin{array}{l}\text { Mindraider } \\
{[38]}\end{array}$ \\
\hline
\end{tabular}

difference in comparison to the first case is that data spans over multiple systems of different types. Therefore, we are presented with the systems integration and data mediation problems.

- interlining Idea Management data with public data. This is a case where assets from Idea Management Systems are linked to data published in other independent systems that are available for public use (e.g. social networking portals). The evolution of the problem in this case, in comparison to the previous, is that there is no control over systems maintained by other companies, and possibly the data as well because it is created by large communities moderated by independent parties.

Each of the mentioned categories can be further detailed, however is has to be noted that at some point the type of the systems that can be interlinked start to be very dependent on the enterprise profile, size and a number of other aspects that determine what kind of IT support systems are used (e.g. a software development company will use different systems to support their management process than a hardware design company). Moreover, while implementing the use cases in practice (see Sec. V), we noticed that the amount of data and it's growth rate in correlation to amount of information submitted to the Idea Management System plays an important role for effectiveness of integration in terms of benefits delivered (e.g. it makes little sense to integrate a bug tracking system that produces a significantly smaller rate of bugs in time than the efficiency of IMS in terms of the implemented ideas). For the reasons above and size limit of the article, we do not describe every single system type and the possibilities that it brings. However, we list the most important systems for idea management per each category, describe their current status with respect to ontologies (see Table I) and later, on top of the presented classification, we chose a particular scenario and detail it on data level so that it can be an inspiration for other cases as well. For more interlinking case studies please refer to Gi2MO project page [39].

\section{A. Scenario case study: Interlinking Innovation Data with Human Resources Management System}

In the following scenario we aim to extract employee characteristics from the Human Resources Management System (HRMS) and try to connect it to the data produced in Idea Management System (IMS) so that we can deliver some additional benefits. The common denominator 


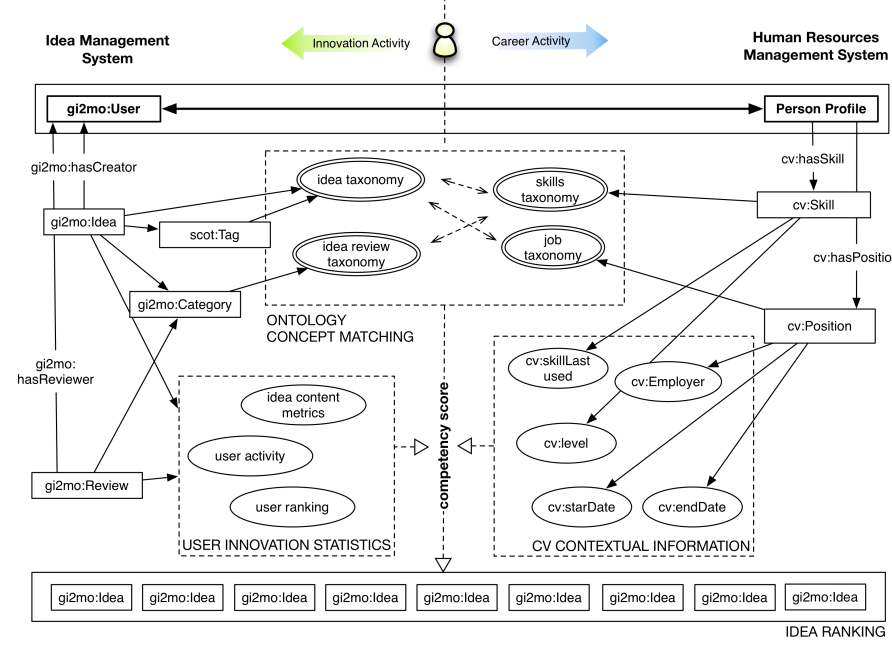

Figure 4. Using links between HRMS and IMS to get deeper understanding of the innovator profile and asses ideas by competencies

of both systems is the concept of the person therefore we can attempt to draw scenarios based on integration on the level of personal profile. In terms of Semantic Web this is most often achieved by using the FOAF ontology for both systems and interlinking the common profile with data in each system (see Fig. 4). The technical particularities of establishing links in each of the systems can be solved by using certain dedicated ontologies (e.g. Gi2MO [4] for Idea Management System and Organization Ontology [25] together with ResumeRDF [27] for HRMS).

Using the links established in such a manner it is possible to relate ideas of given characteristics with personal skills, competencies etc. to achieve a number of goals, for example:

- assess ideas based on the competencies, experience and skills of the person that submitted the idea

- recommend idea reviewers based on their skills and relation to idea topic

- judge the efficiency of idea reviewers or idea submitters based on their activity in the IMS and regular projects of the enterprise (e.g. to promote people who are clearly more active than others in many areas or to see if employees from certain departments are better for participation in the innovation efforts).

\section{Extending the Ontology to FACILITATE INTERLINKING SCENARIOS}

Following the analysis of enterprise systems and their dedicated ontologies, we continued by relating those systems to idea management through enumerating metrics that could be extracted from each and developing the necessary Idea Management ontology extensions that would facilitate the data integration (see Table II).

During our research we encountered a number of problems related to activities of interlinking independent systems using Semantic Web technologies:

- in a number of cases data can be linked indirectly (e.g. bugs linked to ideas via project management system). However this creates a problem when a certain system is not present in particular company environment.

- should the links be established via a single property (could result in big number of properties) or via classes that describe type of relation and additional characteristics

- should there be individual properties for links with every kind of system or generic ones (eg. gi2mo:hasRelated). In case of generic ones the ontology is more simple but processing data becomes more complex (e.g. type of relation can be identified in SPARQL query by checking rdf:type).

- the ontologies established over the past years for enterprise systems were not created with the intent to expose structured data but to perform very specialised tasks related to knowledge management within the scope of those systems. Therefore, not only those ontologies do not facilitate interlinking but in addition often are insufficient for publishing even the most basic data of the systems.

- adding new properties and extending the ontology makes it more powerful and useful but at the same time more complex and harder to comprehand by non Semantic Web experts, while the core design assumption for Gi2MO is to maintain a simple and easy to implement data schema [5].

The choices that we have made in terms of the above problems are reflected in particular decisions for $\mathrm{Gi} 2 \mathrm{MO}$ ontology enhancements presented in Table II. Following the original design assumptions of the Gi2MO ontology in most cases we opt for making the data schema as simple as possible even at the cost of increasing the complexity of SPARQL queries required to extract the data. The ontology extensions presented in Table II lay the foundations for experimenting with different integration scenarios and utilizing extensive links spanning across a number of systems to evaluate the benefits gained from particular datasets. As an example we detail one of such evaluation activities in the next section.

\section{Evaluation of DATA INTERLINKING SCENARIOS}

In the following section we compliment our study by presenting the results of our work implemented in practice. As mentioned earlier (see Sec. II) our primary motivation with regard to enterprise linked data is extracting innovation metrics. A popular way the metrics are utilized in the contemporary Idea Management Systems is in data visualisations. Therefore, to prove that the metrics that we have pointed can be extracted in practice, we followed this notion of data visualisation and constructed an application called Idea Analyst [40] that would map data extracted with SPARQL queries from distributed datasets to bubble charts. 
Table II

LiNKING IDEA MANAGEMENT WITH OTHER SYSTEMS

\begin{tabular}{|c|c|c|c|}
\hline System & Link Example & Metric Example & Gi2MO Properties \\
\hline $\begin{array}{l}\text { Internal IMS } \\
\text { Assets }\end{array}$ & $\begin{array}{l}\text { Link ideas based on } \\
\text { similarty (eg. duplicates, } \\
\text { similar topic, one idea } \\
\text { part of another etc.) }\end{array}$ & $\begin{array}{l}\text { Amount of similar ideas (e.g. with a } \\
\text { certain degree of similarity) }\end{array}$ & $\begin{array}{l}\text { gi2mo:hasRelated, } \\
\text { gi2mo:hasSimilar, } \\
\text { gi2mo:describesPartOf, } \\
\text { gi2mo:hasDuplicate }\end{array}$ \\
\hline & \multicolumn{3}{|c|}{ Global Approaches to Enterprise Management } \\
\hline ERP & $\begin{array}{l}\text { Link idea to financial } \\
\text { data of processes that im- } \\
\text { plements it }\end{array}$ & $\begin{array}{l}\text { Return of Investment for particular im- } \\
\text { plemented ideas }\end{array}$ & gi2mo:hasRelated \\
\hline PLM & $\begin{array}{l}\text { Link ideas to products } \\
\text { that implement them }\end{array}$ & $\begin{array}{l}\text { Amount of resources involved in prod- } \\
\text { uct engineering }\end{array}$ & $\begin{array}{l}\text { gi2mo:hasImplementation, } \\
\text { gi2mo:hasRelated }\end{array}$ \\
\hline & \multicolumn{3}{|c|}{ Specialised (Dedicated) Systems for Enterprise Management } \\
\hline CRM & $\begin{array}{l}\text { Link ideas to client com- } \\
\text { plaint/ suggestion logs }\end{array}$ & $\begin{array}{l}\text { Amount of complaints filed for a prod- } \\
\text { uct that evolved from Idea Management }\end{array}$ & gi2mo:hasRelated \\
\hline SCM & $\begin{array}{l}\text { Link ideas to supply } \\
\text { chain activities that oc- } \\
\text { curred during sales of } \\
\text { products based on ideas }\end{array}$ & $\begin{array}{l}\text { Average delay in product deliveries } \\
\text { based on certain idea }\end{array}$ & $\begin{array}{l}\text { gi2mo:hasRelated, } \\
\text { gi2mo:hasImplementation }\end{array}$ \\
\hline PMS & Link ideas to projects & $\begin{array}{l}\text { Time beyond set deadline that it took to } \\
\text { develop certain product }\end{array}$ & $\begin{array}{l}\text { gi2mo:hasRelated, } \\
\text { gi2mo:hasImplementation }\end{array}$ \\
\hline HRMS & $\begin{array}{l}\text { Link ideas to people in } \\
\text { the company that are } \\
\text { responsible for different } \\
\text { aspects }\end{array}$ & $\begin{array}{l}\text { Employment duration in the company } \\
\text { for idea reviewers }\end{array}$ & $\begin{array}{l}\text { via persons's foaf:Agent having } \\
\text { OnlineAccount in both systems }\end{array}$ \\
\hline \multirow[t]{2}{*}{ CWE } & $\begin{array}{l}\text { Link ideas to documents } \\
\text { and discussions that oc- } \\
\text { cur in the company }\end{array}$ & $\begin{array}{l}\text { Amount of discussions regarding prod- } \\
\text { uct based on idea }\end{array}$ & $\begin{array}{l}\text { gi2mo:hasOrigin, } \\
\text { gi2mo:hasRelated }\end{array}$ \\
\hline & \multicolumn{3}{|c|}{ Product Development Support Systems (Examples for Software Development) } \\
\hline Bug-tracking & $\begin{array}{l}\text { Link ideas to bugs that } \\
\text { were submitted in rela- } \\
\text { tion to their implementa- } \\
\text { tion }\end{array}$ & $\begin{array}{l}\text { Amount of bugs submitted to a product } \\
\text { that implements certain idea }\end{array}$ & $\begin{array}{l}\text { gi2mo:hasImplementation } \\
\text { to project instance or } \\
\text { gi2mo:hasRelated directly } \\
\text { to bug }\end{array}$ \\
\hline SCM & $\begin{array}{l}\text { Link ideas to software } \\
\text { projects that implement } \\
\text { them }\end{array}$ & $\begin{array}{l}\text { Amount of commits in time for changes } \\
\text { based on idea category }\end{array}$ & $\begin{array}{l}\text { gi2mo:hasRelated, } \\
\text { gi2mo:hasImplementation }\end{array}$ \\
\hline $\begin{array}{l}\text { Blog/ } \\
\text { Forum/ } \\
\text { Lists } \\
\end{array}$ & $\begin{array}{l}\text { Link ideas to posts that } \\
\text { discuss them }\end{array}$ & $\begin{array}{l}\text { Amount of comments for post related to } \\
\text { idea }\end{array}$ & $\begin{array}{l}\text { gi2mo:hasRelated, } \\
\text { gi2mo:hasOrigin }\end{array}$ \\
\hline $\begin{array}{l}\text { Separate } \\
\text { IMS } \\
\text { Instances }\end{array}$ & $\begin{array}{l}\text { Link the same ideas } \\
\text { across different language } \\
\text { versions of the IMS de- } \\
\text { ployed by a single com- } \\
\text { pany }\end{array}$ & $\begin{array}{l}\text { Amount of ideas in external systems } \\
\text { related to certain idea }\end{array}$ & $\begin{array}{l}\text { gi2mo:hasRelated, } \\
\text { gi2mo:hasOrigin }\end{array}$ \\
\hline $\begin{array}{l}\text { Social } \\
\text { Networks }\end{array}$ & $\begin{array}{l}\text { Link ideas to posts that } \\
\text { describe their topic }\end{array}$ & $\begin{array}{l}\text { Amount of comments on the topic re- } \\
\text { lated to idea }\end{array}$ & $\begin{array}{l}\text { gi2mo:hasRelated, } \\
\text { gi2mo:hasOrigin }\end{array}$ \\
\hline Wiki & $\begin{array}{l}\text { Link ideas with wiki } \\
\text { pages on which the ideas } \\
\text { are further developed }\end{array}$ & $\begin{array}{l}\text { Number of revisions of a wiki page that } \\
\text { describes an idea }\end{array}$ & $\begin{array}{l}\text { gi2mo:hasRelated, } \\
\text { gi2mo:hasOrigin }\end{array}$ \\
\hline $\begin{array}{l}\text { Patent } \\
\text { Databases }\end{array}$ & $\begin{array}{l}\text { Link ideas to patents that } \\
\text { describe similar topics }\end{array}$ & Amount of patents that cover the idea & gi2mo:hasRelated \\
\hline Mindmaps & $\begin{array}{l}\text { Link ideas to particular } \\
\text { mindmaps that describe } \\
\text { them }\end{array}$ & Amount of concepts that create the idea & $\begin{array}{l}\text { gi2mo:hasRelated, } \\
\text { gi2mo:hasOrigin }\end{array}$ \\
\hline
\end{tabular}

In our implementation data series for a multidimensional diagram are first extracted independently from each of the datasets and then bound together by a common concept that must be present in each result set. For example values used to visualise the radius of spheres plotted onto the chart have to refer to the same root property in the Idea Management System (e.g. idea URI) as values extracted by another query that delivers sphere fill color values. Furthermore, as we noticed when working with particular datasets, most of the data that is published in the linked data cloud as well as web systems related to idea management is not numerical. Therefore, one important observation is the necessity of using the SPARQL endpoint implementation that supports aggregate functions (COUNT, SUM, MIN, MAX etc.).
Having met the above requirements, the Idea Analyst application was used to experiment with the interlinking scenarios we proposed in the previous sections. Here we present one of them - extracting metrics derived from the integration between Idea Management System and HRMS.

In this case study rather than assessing ideas we use the data to recognize the effectiveness of employees as ideas authors. This is visualised by comparing the amount of skills that employees have to the amount of ideas that they created and amount of those ideas that have proven successful enough to get implemented.

The main ontologies used are: Gi2MO for Idea Management System and ResumeRDF [41] for HRMS. The idea management dataset comes from one of the publicly 


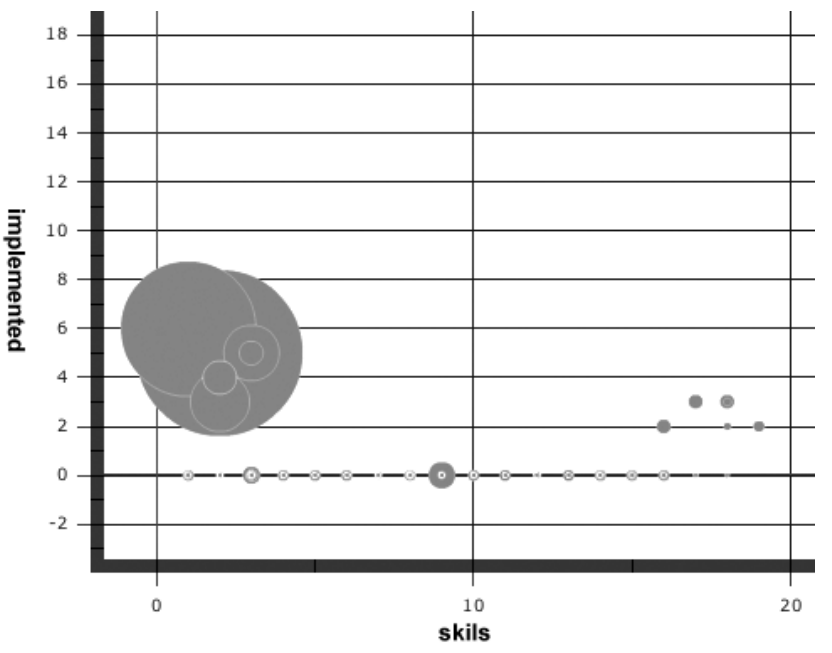

- skills vs. implemented per foaf_person_uri

Figure 5. A sample bubble chart generated by the Idea Analyst application based on SPARQL queries run over particular RDF datasets

available instances [42], whereas the HRMS dataset was prepared manually without relation to any particular system.

To visualise the data we created a 2 dimensional bubble chart with two data series mapped to $\mathrm{x}$ and $\mathrm{y}$ axis while the third data series is mapped as the sphere diameter.

The end result is a bubble chart where it can be observed that on top of the huge number of ideas that never get implemented the two most valuable groups of employees for the companies innovation policy are: people with very little technical knowledge but huge motivation (a large number of submitted ideas) and very skilled people that share just a few ideas but almost always are successful (see Fig. 5).

\section{RELATED WORK}

In the paper we discuss knowledge management issues present in Idea Management Systems and propose a solution by establishing Linked Enterprise Data. While to our knowledge this particular solution has not been tested in context of idea management, there is a number of different approaches that relate to our work in both the research fields of innovation management and the Semantic Web.

In relation to exclusively Idea Management Systems, Hrastinski et al. [43] surveyed a number of selected products and pointed out that the current commercial systems employ rather simple idea evaluation methods most often being analysis of community statistics (number of ideas per user, community voting results, number of idea comments etc.) or internal business metrics that are delivered by designated experts. On the other hand, shifting towards the scientific research in the area, there have been various approaches that attempted to find a solution to time efficient and effective automatic idea assessment problem e.g. with prediction markets [44], by applying problem solving algorithms [45] or calculating metrics for the quality of management [46] However, non of those did direct towards the use of metadata to integrate idea management with other business systems as we propose. The previous research that does take into consideration use of ontologies most often is discussed in context of innovation management which is a more broad yet also more generic point of view on innovation than Idea Management Systems. For instance, Ning el at. [47] introduces a vision of the semantic extended enterprise where Semantic Web technologies are used to collect similar data from different innovation oriented systems yet omits the particularities of using different ontologies in systems distributed across the enterprise. To our knowledge, specifically in the area of Idea Management Systems and Semantic Web, only Rield et al. [48] proposed an ontology for describing the Idea Management System data structure similar as Gi2MO project [5] but neither of the project did yet discuss the ontology in the context of interoperability with other enterprise systems and their dedicated ontologies.

In relation to Semantic Web research carried out for other domains and Linked Data approaches to the enterprise environment modelling there have been numerous solutions proposed. In many cases, the research carried out so far focuses on very specific systems - the most relevant ones from the point of view of Idea Management have been already presented in Table I. In those solutions, when approaching knowledge management problems, in most cases the focus is put on getting deep into details of representing domain specific knowledge or system structure and taking advantage of this with various reasoning scenarios [49]. Contrary to such methods in our work we simplify the technical approach and attempt to direct the research effort towards investigating benefits that come from particular links between the data of very different systems. As such, from the technical and conceptual point of view, we align our vision of Semantic Web in the enterprise more to the principles presented by the Linking Open Data project [3], however with the obvious distinction of not publishing the data in the open and just using the same lightweight data linking approach. There have been some initial initiatives for establishing Enterprise Linked Data but so far the focus has been put on pulling the information from the Linked Open Data cloud into the enterprise and reusing it [50]. In our work, we also notice the huge benefit of open data for the enterprise but at the same time we dedicate to the concept of creating an Enterprise Linked Data cloud that would be private and individual for a given corporation.

Finally, in relation to using the Linked Data in practice, as part of our evaluation we presented the notion of generating charts over the interlinked datasets. Similar work on calculating metrics over the open datasets has been presented by Zembowicz et al. [51]. In comparison to our implementation that evaluates charting in a particular domain, Zembowicz focuses more on the user interface side 
and translating between complex SPARQL queries to enable a simple human-computer interaction method.

\section{CONCLUSIONS AND FUTURE WORK}

In the following paper we have presented the techniques of interlinking data from Idea Management Systems with other enterprise and public data. On top of proposing a classification for such activities, we have recognized the benefits that could come from each particular case, tested our claims in practice by exploiting the linked data to generate innovation metrics and proposed a solution to plot this data onto charts. By doing so, we have showed how to make a transition from a distributed interconnected data model into its visual, organized representation.

Furthermore, one of the important observations we made during our analysis of Semantic Web efforts in enterprise domain was that most of the ontologies available were not created with Linked Data in mind. Therefore, we have presented a methodology that leads to extending such data schemas towards implementing lightweight enterprise data linking. As an example we have used the ontology for Idea Management Systems (Gi2MO) and applied our methodology to produce it's new iteration.

We performed the practical experiments with forming SPARQL queries for particular datasets that delivered invaluable experience that showed us the weaknesses of both our own ontology but also RDF query language and potential directions for improvement. Some of the most important issues that we noticed during performing the research described in this paper are:

- we point what data to link, what kind of data schemas to use, we prepare the facilities to do it, finally we show the benefits but we assume that the links will already be there. We do not deliver a solution to establish them, which ultimately should be delivered as well to achieve success for practical implementations.

- a number of linking benefits and metrics that we point out gain on value when established based on detecting similarities between ideas. However, yet again we only deliver the solution to describe relationships between ideas we do not give a solution to actually link them.

- finally, some of the datasets used for evaluation were not coming from real functional systems. Parts (especially the links) were generated manually therefore it can be doubtful as a genuine proof. What is truly needed is full evaluation on live data coming from real systems.

Whereas some of the above issues are still mentioned in terms of future work, the progress on others can be observed on the Gi2MO homepage [39]. We decided not to bring bigger attention to any them here because of the size limitation of the article and our main intention to focus on aspects of ontology as a data schema and activities involved in its evolution towards fitting to the notion of cross system linked data. In addition, with this article we would like to emphasize that one of the practical ways to prove Semantic Web and Linked Data potential can be through analysing the data connections with the goal to generate metrics and statistics not available otherwise. On the road to achieving this, we aim to continue working towards improving idea assessment facilities in Idea Management Systems by enriching our Idea Analyst solution with data filtering capabilities and new lines of research for exploiting the interlinked data in all phases of the Idea Life Cycle.

\section{ACKNOWLEDGEMENTS}

This research has been partly funded by the Spanish Ministry of Industry, Tourism and Trade through the project RESULTA (TSI-020301-2009-31) and Spanish CENIT project THOFU. We express our gratitude to Atos Origin R\&D for their support and assistance.

\section{REFERENCES}

[1] T. Berners-Lee, "Semantic web road map," 1998.

[2] L. Feigenbaum, I. Herman, T. Hongsermeier, E. Neumann, and S. Stephens, "The semantic web in action," Scientific American, January 2009.

[3] "Linking open data project website." [Online]. Available: http://esw.w3.org/SweoIG/TaskForces/CommunityProjects/ LinkingOpenData

[4] "Gi2mo ontology specifrication." [Online]. Available: http://purl.org/gi2mo/ns

[5] A. Westerski, C. A. Iglesias, and F. T. Rico, "A model for integration and interlinking of idea management." in Metadata and Semantic Research: 4th International Conference, MTSR 2010, Alcalá de Henares, Spain, 2010.

[6] C. Riedl, N. May, J. Finzen, S. Stathel, T. Leidig, V. Kaufman, R. Belecheanu, and H. Krcmar, "Managing service innovations with an idea ontology," in Proceedings of XIX International RESER Conference, September 24th-26th 2009, Budapest, Hungary, 2009.

[7] "Idea ontology vocabulary specification." [Online]. Available: http://www.ideaontology.org/spec/

[8] F. Gailly and G. Poels, "Towards an owl formalization of the resource event agent business domain ontology," in Proc. 10th Int'l Conf. Business Information Systems, LNCS, 2005.

[9] A. Bialecki, "Rea ontology formalization." [Online]. Available: http://www.getopt.org/ecimf/contrib/onto/REA/

[10] D. E. O'Leary, "On the relationship between rea and sap," International Journal of Accounting Information Systems, vol. 5, no. 1, pp. $65-81,2004$.

[11] M. S. Fox and M. Gruninger, "Enterprise modeling," $A I$ Magazine, vol. 19, no. 3, 1998. 
[12] M. Uschold, M. Uschold, M. King, M. King, S. B. R. House, S. Moralee, S. Moralee, Y. Zorgios, and Y. Zorgios, "The enterprise ontology," The Knowledge Engineering Review, vol. 13, 1995.

[13] J. Gordijn and H. Akkermans, "Value based requirements engineering: Exploring innovative e-commerce ideas," $R e$ quirements Engineering Journal, vol. 8, 2002.

[14] A. Osterwalder and Y. Pigneur, "An e-business model ontology for modeling e-business," in 15th Bled Electronic Commerce Conference, 2002.

[15] N. Khanna, "An ontology for a lean supply chain," Master's thesis, Wichita State University, 2003.

[16] C.-S. Lee, Y.-C. Wang, W.-M. Liu, and Y.-C. Lin, "Crm ontology based on cmmi project planning for business application," in 2007 International Conference on Machine Learning and Cybernetics, 2007.

[17] D. Magro and A. Goy, "Towards a first ontology for customer relationship management," in Proceedings of the 5th international conference on Soft computing as transdisciplinary science and technology, Cergy-Pontoise, France, 2008.

[18] H. Liwen and X. Min, "Research on modelling customer ontology under crm framework," in PACIS 2004 Proceedings, 2004.

[19] L. Yiqing, L. Lu, and L. Chen, "Decision-making for supplier selection based on ontology and rules," in Second International Conference on Intelligent Computation Technology and Automation, 2009. ICICTA '09., April 2009.

[20] C. Chandra and A. Tumanyan, "Ontology driven knowledge design and development for supply chain management," in Proceedings of IERC'2004,, 2004.

[21] S. Abels, F. Ahlemann, A. Hahn, K. Hausmann, and J. Strickmann, "Promont - a project management ontology as a reference for virtual project organizations," in On the Move to Meaningful Internet Systems 2006: OTM 2006 Workshops, 2006.

[22] "Project metrics ontology." [Online]. Available: http://www.daml.org/ontologies/349

[23] "It-code." [Online]. http://www.civil.auc.dk/ i6ycl/itcode

Available:

[24] E. Dumbill, "Description of a project ontology." [Online]. Available: http://trac.usefulinc.com/doap

[25] D. Reynolds, "Organization ontology." [Online]. Available: http://www.epimorphics.com/public/vocabulary/org.html

[26] A. Gómez-Pérez, J. Ramírez, and B. Villazón-Terrazas, "An ontology for modelling human resources management based on standards," in Proceedings of the 11th international conference, KES 2007 and XVII Italian workshop on neural networks conference on Knowledge-based intelligent information and engineering systems: Part I, Berlin, Heidelberg, 2007.
[27] U. Bojars and J. G. Breslin, "Resumerdf: Expressing skill information on the semantic web." in First International ExpertFinder Workshop, Berlin, Germany, 2007.

[28] D. Lee, V. Peristeras, and N. Loutas, "Reusing the sioc ontology to facilitate semantic cwe interoperability," in $\mathrm{On}$ the Move to Meaningful Internet Systems 2008, 2008.

[29] "Bug and enhancement tracking language." [Online]. Available: http://code.google.com/p/baetle/

[30] L. de Oliveira Arantes, R. de Almeida Falbo, and G. Guizzardi, "Evolving a software configuration management ontology." in II Workshop on Ontologies and Metamodeling in Software and Data Engineering., 2007.

[31] H. H. Shahri, J. A. Hendler, and A. A. Porter, "Software configuration management using ontologies," in Proceedings of the 3rd International Workshop on Semantic Web Enabled Software Engineering at the 4th European Semantic Web Conference (ESWC'07), Innsbruck, Austria, 2007.

[32] J. G. Breslin, A. Harth, U. Bojars, and S. Decker, "Towards semantically-interlinked online communities." in In Proceedings of the 2nd European Semantic Web Conference (ESWC '05), Heraklion, Greece, 2005.

[33] S. Fernandez, D. Berrueta, and J. E. Labra, "A semantic web approach to publish and consume mailing lists," International Journal on WWW/Internet, vol. 6, no. 1, 2008.

[34] D. Brickley and L. Miller, "Foaf vocabulary specification." 2010. [Online]. Available: http://xmlns.com/foaf/spec/

[35] M. Krotzsch and D. Vrandecic, "Swivt ontology specification." [Online]. Available: http://semanticmediawiki.org/swivt/

[36] M. Krötzsch, D. Vrandecic, D. Vr, and M. Völkel, "Wikipedia and the semantic web - the missing links," in Proceedings of Wikimania 2005, 2005

[37] M. Giereth, S. Koch, Y. Kompatsiaris, S. Papadopoulos, E. Pianta, L. Serafini, and L. Wanner, "A modular framework for ontology-based representation of patent information," in Proceeding of the 2007 conference on Legal Knowledge and Information Systems: JURIX 2007: The Twentieth Annual Conference, Amsterdam, Netherlands, 2007.

[38] "Mindraider homepage." [Online]. Available: http://mindraider.sourceforge.net/semantic-web.html

[39] "Gi2mo project homepage." [Online]. Available: http://www.gi2mo.org/

[40] "Ideaanalyst webpage." [Online]. Available: http://gi2mo.org/apps/idea-analyst

[41] "Resumerdf ontology specification." [Online]. Available: http://rdfs.org/resume-rdf/

[42] "Adobe acrobat ideas." [Online]. Available: http://na5.brightidea.com/ct/ctlist.bix?c=8FBBEA8FD8E6-4E34-A7C1-7C74FB3B4EFA 
[43] S. Hrastinski, N. Z. Kviselius, and M. Edenius, "A review of technologies for open innovaton: Characteristics and future trends," in Proceedings of the 43rd Hawaii International Conference on System Sceiences, 2010.

[44] E. Bothos, D. Apostolou, and G. Mentzas, "Idem: A prediction market for idea management. designing e-business systems. markets, services, and networks," in 7th Workshop on E-Business, WeB 2008, Paris, France, 2008.

[45] E. D. Adamides and N. Karacapilidis, "Information technology support for the knowledge and social processes of innovation management," Technovation, vol. 26, no. 1, pp. 50-59, 2006.

[46] S. J. Conn, M. T. Torkkeli, and I. Bitran, "Assessing the management of innovation with software tools: an application of innovationenterprizer," International Journal of Technology Management, vol. 45, no. 3/4, pp. 323-336, 2009.

[47] K. Ning, D. O'Sullivan, Q. Zhu, and S. Decker, "Semantic innovation management across the extended enterprise," International Journal on Industrial and Systems Engineering, vol. 1, 2006.

[48] C. Riedl, N. May, J. Finzen, S. Stathel, V. Kaufman, and H. Krcmar, "An idea ontology for innovation management," International Journal on Semantic Web and Information Systems, 2009.

[49] P. Mika and H. Akkermans, "Analysis of the state-of-the-art in ontology-based knowledge management," Vrije Universiteit, Amsterdam, Tech. Rep., 2003.

[50] D. Wood, Linking Enterprise Data. Springer, 2010.

[51] F. Zembowicz, D. Opolon, and S. Miles, "openchart: Charting quantitive properties in lod," in LDOW2010, 2010. 